\title{
IMPRENTA Y CRÍTICA TEXTUAL: LA ICONOGRAFÍA DEL LIBRO DE LAS MARAVILLAS DEL MUNDO DE JUAN DE MANDEVILLA
}

\author{
MARÍA MERCEDES RODRÍGUeZ TEMPERLEY \\ IIBICRIT-SECRIT (CONICET) \\ Universidad Nacional de La Plata
}

\begin{abstract}
RESUMEN
El surgimiento de la imprenta significó un cambio sustantivo en el modo de circulación de los textos, hasta entonces de difusión manuscrita, e implicó asimismo un grado de participación cada vez mayor de impresores y cajistas sobre las obras, en detrimento de la figura autorial. Entre las innovaciones introducidas se destaca la inclusión de grabados xilográficos, destinados a ilustrar secciones del texto o a funcionar como recurso mnemotécnico. Sin embargo, dicho corpus xilográfico ha sido a menudo olvidado por los editores modernos, quienes al momento de realizar ediciones críticas de impresos antiguos, privilegian - comprensiblemente- las variantes textuales, pero por lo general omiten toda referencia a las variaciones iconográficas. En nuestra edición crítica de los cinco impresos castellanos del siglo XVI del Libro de las maravillas del mundo, de Juan de Mandevilla, advertimos que las xilografías varían de una edición a otra, llegando incluso a desviar el significado del texto escrito o introduciendo variantes textuales sólo explicables en relación con las imágenes que acompañan el texto. Por ello, consideramos que el aparato crítico debería dar cuenta de estos cambios iconográficos del mismo modo en que lo hace con las variantes léxicas.
\end{abstract}

Palabras clave: imprenta, crítica textual, iconografía, edición de textos.

\section{PRINTING AND TEXTUAL CRITICISM: THE ICONOGRAPHY IN JOHN MANDEVILLE'S LIBRO DE LAS MARAVILLAS DEL MUNDO}

\begin{abstract}
The rise of printing changed the mode of transmission of literary texts. Also, printing implied an increased participation of printers in the works, who often introduced changes in the original text. Some of these changes were the woodcuts and engravings that accompanied many of the early editions, used to illustrate some chapters or to function as mnemonic device. However, this 'corpus xylographic' has been forgotten often by modern editors. On preparing critical editions of old prints books, textual variants are considered and studied, but usually modern editors omit any reference to iconographic variations.

In our critical edition of sixteenth-century Castilian versions of John Mandeville's Libro de las maravillas del mundo, we find many changes in the woodcuts between the different
\end{abstract}


editions. Frequently, some textual variations are the consequence on trying to describe a woodcut. So, we think that in any critical edition, the critical apparatus should account for these iconographic changes as it does with lexical variants.

Key Words: printing, textual criticism, iconography, critical editions..

El presente trabajo, surgido a partir de la realización de una edición crítica del Libro de las maravillas del mundo y Viaje de la Tierra Sancta de Jerusalem $(L M M)$ en sus versiones castellanas impresas del siglo XVI', se propone rescatar el lenguaje iconográfico de los impresos del libro de Juan de Mandevilla, no tanto en su estética o estilo artístico sino en la importancia que adquieren las imágenes en el proceso de edición crítica de un texto.

Partimos de una premisa que, de tan obvia, aparece como un hecho incuestionado: la paradoja en que caen muchos editores modernos, quienes a la hora de editar textos de los siglos XV y XVI, frecuentemente prescinden de manera absoluta del lenguaje iconográfico que los acompañaba en su formato original. En todo trabajo de edición, lógicamente, se analizan y sopesan cuidadosamente las variantes textuales, mientras que el lenguaje iconográfico suele considerarse como un componente casi ajeno al texto, convirtiéndose así en una suerte de variante escamoteada en el trabajo editorial. Esto da como resultado la manipulación de un objeto cultural (en este caso, un libro impreso que incluye grabados) para —bajo el argumento de una edición crítica que reconstruya un arquetipo textual o que dé cuenta de las variaciones sufridas por el texto a través del tiempo-, someterlo en realidad a un «vaciamiento de significado» que nos aleja de los textos concretos, es decir, de las versiones efectivamente leídas en la época, las cuales pueden aportar elementos valiosos acerca de los tipos de lectura, de la circulación de textos literarios, de las diversas traducciones de una misma obra y de las relaciones entre impresores (fundamentalmente, a partir del acostumbrado alquiler o préstamo de tacos xilográficos y tipografías). El análisis iconográfico, además, permite iluminar la comprensión acerca de los modos de creación en los diversos talleres de imprenta y los procedimientos llevados adelante por los editores para identificar un producto destinado al éxito comercial.

Este respeto por el soporte o formato original en el que circulaban dichos textos no significa comulgar con las posturas extremas de Bernard

\footnotetext{
${ }^{1}$ RODRÍGUEZ TEMPERLEY, María Mercedes (ed.). Juan de Mandevilla: Libro de las marauillas del mundo y del Viaje de la Tierra Sancta de Jerusalem (Impresos castellanos, siglo XVI). Edición crítica, estudio preliminar y notas. Buenos Aires: IIBICRIT-SECRIT (Incipit Publicaciones, Ediciones Críticas 6), 2011.
} 
Cerquiglini $^{2}$ en cuanto a la variación permanente de los textos medievales que los define en su característica identitaria, ni mucho menos con el extremismo invalidante de John Dagenais ${ }^{3}$ y su paradigma escriptural, que considera la materialidad de los manuscritos y códices medievales como única aproximación válida a los textos del periodo. Simplemente, buscamos insistir sobre un aspecto desatendido con frecuencia por la disciplina ecdótica de un modo un tanto inexplicable. No debemos soslayar el hecho de que, más a menudo de lo que se cree, los grabados generan amplificaciones textuales o interpolaciones, mientras que otras veces, como ya veremos, determinadas lecciones o variantes sólo se explican por la presencia de un grabado. Entendemos que la riqueza del corpus iconográfico no debe soslayarse en la edición crítica sino, por el contrario, sistematizarse de algún modo particular en el aparato crítico, ya que las variantes xilográficas pueden clasificarse del mismo modo que las variantes textuales: adición, omisión, alteración, etc.

En el caso del Libro de las maravillas, de Juan de Mandevilla, la historia de transmisión textual adquiere ribetes más que interesantes por su complejo itinerario, que incluye traducciones al aragonés y al castellano, y la circulación peninsular en formato manuscrito e impreso. En primer lugar, se trata de un texto redactado originariamente en anglonormando a mediados del siglo XIV, que llega por primera vez a la Península a fines de dicho siglo en una traducción aragonesa (existen también noticias de traducciones catalanas, probablemente del siglo XV, hoy perdidas). De esta tradición manuscrita hispánica sólo se conserva el manuscrito aragonés MIII-7, guardado en la biblioteca de El Escorial, y del cual realizáramos una edición crítica en $2005^{4}$.

Posteriormente, ya en tiempos de la imprenta, el libro reverdece y se difunde, traducido al castellano, a través de cuatro ediciones valencianas (Jorge Costilla, 1521; [¿Juan Joffre?], 1524; Jorge Costilla, 1531 y Juan Navarro, 1540) y de una publicada en Alcalá de Henares en 1547 [¿Juan de Brocar?] $]^{5}$. Estas traducciones castellanas, sin embargo, no derivan del

\footnotetext{
${ }^{2}$ CERQUIGLINI, Bernard. Eloge de la variante. Histoire critique de la philologie. Paris: Seuil, 1989.

${ }^{3}$ DAGENAIS, John. The Ethics of Reading in Manuscript Culture: Glossing the «Libro de buen amor». Princeton: Princeton University Press, 1994.

${ }^{4}$ RODRÍGUEZ TEMPERLEY, María Mercedes (ed.). Juan de Mandevilla: Libro de las maravillas del mundo (Ms. Esc. M-III-7). Edición crítica, estudio preliminar y notas. Buenos Aires: Secrit. 2005, Serie Ediciones Críticas, 3.

${ }^{5}$ Valencia: Jorge Costilla, 1521 (British Library, C20.e.32); Valencia: [¿Juan Joffre?], 1524 (Biblioteca Nacional de Madrid, R 13148; Biblioteca Comunale di Mantova, q-IV59); Valencia: Jorge Costilla, 1531 (Hispanic Society of America, New York, G370 M2.M3618 1531, olim 107 M31; Valencia: Juan Navarro, 1540 (British Library C.55.g.4 y Biblioteca-Museo Balaguer, A-F8, G-H6); Alcalá de Henares: [¿Juan de Brocar?], 1547, (British Library, 149.e.6).
} 
manuscrito aragonés (perteneciente a la rama continental dentro de la familia de los testimonios europeos) sino que provienen de una tradición híbrida (continental e insular) ${ }^{6}$, probablemente derivada de algún manuscrito francés en el cual ya estuvieran entrelazadas ambas ramas, como el de la BNF, Fonds Smith Lesouëf 65 [P15 $]^{7}$. Para clausurar este círculo itinerante o suerte de tradición laberíntica, el modelo iconográfico seguido por los impresos castellanos es indudablemente de origen alemán (el editado por Anton Sorg en Augsburgo, en 1480), según puede advertirse con sólo observar los grabados que lo ilustran, copiados por los impresores hispánicos, si bien éstos incurren ocasionalmente en ciertos desvíos, algunos de los cuales serán objeto de nuestro estudio ${ }^{8}$.

Uno de los aportes de nuestro trabajo, consistente en la realización de las ediciones críticas del Libro de las maravillas del mundo en sus traducciones peninsulares, radica en presentar y completar el estudio de las versiones hispánicas de este libro de viajes en su íntegra dimensión (etapa manuscrita / etapa impresa), procedimiento que permite verificar las variaciones y manipulaciones a las que son sometidos los textos literarios en los primeros años de la imprenta y reconocer la complejidad del proceso lite-

${ }^{6}$ Sobre las tradiciones insular y continental del Libro de las maravillas, ver el capítulo A.3. Familia textual de nuestra edición del manuscrito escurialense (RODRÍGUEZ TEMPERLEY, 2005, op.cit., pp. LXXII-LXXIV).

${ }^{7}$ Dicho manuscrito ha sido estudiado, en relación con la tradición castellana, por Alda ROSSEBASTIANO (La tradizione ibero-romanza del «Libro de las maravillas del mundo», di Juan de Mandavila. Alessandria: Studi, 1997) y más recientemente por Lidia BARTOLUCCI en dos trabajos ( A proposito delle versioni castigliani a stampa di Jean de Mandeville». Aevum, 2008, 82: 3, pp. 611-620; «Intorno al Ms. P15 di Jean de Mandeville». En: BABBI, Anna María; Silvia BIGLIAZZI, y Gian Paolo MARCHI (eds.). Bearers of a tradition. Studi in onore di Angelo Righetti. Verona: Edizioni Fiorini, 2010, pp. 19-25). La investigadora italiana se inclina por considerarlo como un modelo muy próximo sobre el cual se realizó la traducción castellana: «Circa il modello da cui derivano le stampe castigliane, diversamente sia da Marsh, che ipotizza una redazione latina, sia da Alda Rossebastiano, che li vuole derivati da un ms. continentale per la prima parte e solo per la parte finale da un testimone della Versione Insulare, riteniamo che il ms. guida da cui viene effettuata la traduzione castigliana sia un unico ms. che contiene un testo 'ibrido' como P15» (p. 619). Si bien coincidimos con su opinión en líneas generales, guardamos ciertos reparos para aceptar todos los ejemplos que propone en su frondoso artículo, ya que tenemos una interpretación diferente para el origen de algunos de ellos. Al respecto, ver el Estudio Preliminar a nuestra edición (2011, pp. LXV-LXX).

${ }^{8}$ Sobre los impresos de la obra de Mandevilla en Alemania, ver Josephine W. BENNETT (The rediscovery of Sir John Mandeville. New York: Modern Language Association, 1954, pp. 364-371). La primera edición alemana con estampas corresponde a c. 1478. Tena Tena, quien estudió las xilografías del impreso castellano de 1524, elige la de 1481 porque es la que considera que comparte mayor número de ilustraciones con la mencionada edición hispánica, objeto de su estudio (TENA TENA, Pedro. «Fuentes germanas en grabados de un texto de viaje a Tierra Santa: Juan de Mandeville (Valencia, 1524)». Gutenberg-Jahrbuch, 1996, 71, pp. 80-87). 
rario, en el que resultan claramente distinguibles una etapa de creación y una etapa de transmisión y recepción. Es en esta última donde reconocemos casos en los que las variaciones operadas sobre las obras literarias llegan a conformar un texto sustancialmente distinto al que tuviera lugar en su génesis primaria, fenómeno significativo y desconcertante para los estudiosos de la literatura y de la figura autorial de distintos períodos.

Tal como ya apuntáramos en trabajos anteriores ${ }^{9}$, los cambios textuales introducidos en las traducciones castellanas del $L M M$, fundamentalmente sobre temas dogmáticos y religiosos, distinguen las versiones mandevillescas del siglo XVI de las tempranas del XIV, más cercanas al arquetipo. Así, mientras el $L M M$ es un ejemplo de tolerancia religiosa según los manuscritos conservados del siglo XIV, en las versiones impresas castellanas del XVI Mandevilla se convierte en un intransigente defensor de la ortodoxia católica, amplificando pasajes referidos a los sacramentos, modificando el léxico en aras de una mayor precisión terminológica en cuestiones dogmáticas, omitiendo pasajes sobre creencias supersticiosas, morigerando críticas hacia los cristianos y el clero, moralizando viñetas que ilustraban pasajes del texto o añadiendo grabados de temática religiosa, entre otros procedimientos estudiados.

Como han señalado filólogos de la talla de Pasquali, Contini y Orduna, cada texto a editar presenta su propia problemática, motivo por el cual deberán adaptarse los principios teóricos y metodológicos de la ecdótica para cada caso particular. Para tomar el símil poético de Alberto Blecua, más a menudo de lo que quisiéramos, el paseo seguro por entre los árboles del huerto teórico no nos brinda la experiencia necesaria para una travesía por la confusa selva de la práctica ${ }^{10}$. Apelamos entonces a la repetida definición del maestro Contini, por la cual toda edición crítica no es más que una «hipótesis de trabajo» ${ }^{11}$. Esto nos obliga a replantearnos la idea de «texto en el tiempo», en la que tanto insistía Germán Orduna: «Cada texto tiene su historia: historia de creación e historia de transmisión y recepción» ${ }^{12}$.

Y es dentro de esta historia textual donde se encarna la problemática presente en la edición crítica del $L M M$ con respecto al «lenguaje icono-

${ }^{9}$ RODRÍGUEZ TEMPERLEY, María Mercedes. «Variaciones textuales y cambios culturales en un libro de viajes. El caso de Juan de Mandevilla en España». En: ORDUNA, Germán et al. Estudios sobre la variación textual. Prosa castellana de los siglos XIII a XVI. Buenos Aires: Secrit (Incipit Publicaciones, 6), 2001, pp. 169-195, e «Imprenta y variación textual: el caso de Juan de Mandevilla». Incipit, 2005-2006, XXV-XXVI, pp. 526-536.

${ }^{10}$ BLECUA, Alberto. Manual de Crítica Textual. Madrid: Castalia, 1983, p. 12.

${ }^{11}$ CONTINI, Gianfranco. Breviario di ecdotica. Milano-Napoli: Riccardo Ricciardi Editore, 1986 [1970], p. 74.

12 ORDUNA, Germán. Ecdótica. Problemática de la edición de textos. Kassel: Edition Reichenberger, 2000, p. 2. 
gráfico» de la primera imprenta: resulta insoslayable el hecho de que los cinco impresos castellanos del siglo XVI no solamente presentan variantes textuales de interés, sino que también los grabados que ilustran su contenido varían —en ciertos casos muy significativamente- de una edición a otra.

Como ya hiciéramos referencia, las xilografías utilizadas en las ediciones castellanas son calcos que copian las entalladuras pertenecientes a uno de los primeros impresos alemanes ilustrados del $L M M$, el editado por Anton Sorg en Augsburgo, en 1480. Dicha edición germana resultaría así una especie de «arquetipo iconográfico» del cual derivaría el lenguaje xilográfico de los impresos peninsulares. Sin embargo, se producen variantes significativas, que analizaremos más adelante a través de ejemplos, y que nos develan el carácter creativo e interventor de los impresos castellanos con respecto a otras tradiciones impresas europeas del $L M M^{13}$.

Éstos no innovan sólo en la materia textual sino también en la iconografía: los impresos de Valencia y Alcalá cambian algunos de los grabados originales de las ediciones alemanas y los reemplazan por otros provenientes del Liber Chronicarum de Hartmann Schedel (Nüremberg: Anton Koberger, 1493), de la Legenda Aurea Sanctorum (Basel: Nicolaus Kesler, 1486), del Libro del juego de las suertes de Lorenzo Spirito [Valencia: Jorge Costilla, 1515], de La vida y fabulas de Ysopo (Valencia: Juan Joffre, 1520), de la Suma de todas las crónicas del mundo (Valencia: Jorge Costilla, 1510) o de los libros de caballerías, entre otros, lo cual incide indiscutiblemente en el producto final, en una época en donde aún no está divulgada la lectura masiva y en la cual todavía la cultura icónica se utiliza como medio de difusión para aquellos que no saben leer ${ }^{14}$.

${ }^{13} \mathrm{Al}$ respecto, cabe mencionar que también los impresos franceses (como los de Lyon c. 1490 y Lyon c. 1508) reproducen los grabados de los impresos alemanes. Sin embargo, consideramos importante aclarar que, mientras los impresos franceses copian fielmente las estampas de Sorg (al punto de entrar en duda si no se tratará de los mismos tacos xilográficos, alquilados o tomados en préstamo), las ediciones castellanas recrean constantemente detalles (en la vestimenta, en el armamento, en el paisaje, etc.). Por ello, distinguimos la labor claramente creativa de los ilustradores castellanos.

${ }^{14}$ Para ilustrar esta idea, ver el capítulo C.3. Variación iconográfica del Estudio Preliminar a nuestra edición crítica de los impresos castellanos del Libro de Mandevilla (RODRÍGUEZ TEMPERLEY, 2011). 


\begin{tabular}{|l|c|c|c|c|c|}
\hline \multicolumn{1}{|c|}{ Filiación de xilografias } & 1521 & 1524 & 1531 & 1540 & 1547 \\
\hline LMM (Augsburgo: Anton Sorg, 1481) & $*$ & $*$ & $*$ & $*$ & $*$ \\
\hline $\begin{array}{l}\text { Liber Chronicarum de H. Schedel (Nürem- } \\
\text { berg: Anton Koberger, 1493) }\end{array}$ & $*$ & $*$ & $*$ & $*$ & - \\
\hline $\begin{array}{l}\text { Libro del juego de las suertes, de L. Spirito } \\
\text { [Valencia: Jorge Costilla, 1515] }\end{array}$ & $*$ & $*$ & $*$ & - & $*$ \\
\hline $\begin{array}{l}\text { La vida y fabulas de Ysopo (Valencia: Juan } \\
\text { Joffre, 1520) }\end{array}$ & - & $*$ & - & - & - \\
\hline $\begin{array}{l}\text { Suma de todas las cronicas del mundo } \\
\text { (Valencia: Jorge Costilla, 1510) }\end{array}$ & - & - & - & $*$ & $*$ \\
\hline $\begin{array}{l}\text { Legenda Aurea Sanctorum (Basel: Nicolaus } \\
\text { Kesler, 1486) }\end{array}$ & - & - & - & - & $*$ \\
\hline ??? (estampas de Cristo y la Virgen) & - & $*$ & - & - & - \\
\hline ??? (estampas de la Virgen María) & - & $*$ & $*$ & $*$ & $*$ \\
\hline ??? (estampas de escenas guerreras) & - & $*$ & $*$ & - & $*$ \\
\hline ??? (estampas de temas diversos) & $*$ & $*$ & - & - & $*$ \\
\hline
\end{tabular}

En esta «selva confusa de la práctica» nuestra «hipótesis de trabajo» considera válido realizar una edición crítica ciñéndonos no sólo a las variantes textuales sino buscando el modo de dar cuenta de toda la riqueza iconográfica que, como un «texto segundo», guiaba a los receptores en la interpretación, llegando en ciertos casos a desviar el significado del relato o a introducir variantes textuales en función de los grabados existentes. Estamos en un todo de acuerdo con Rubio Tovar cuando afirma que no es posible considerar las miniaturas «como algo externo al texto, sino como parte de él» ${ }^{15}$. Dar cuenta de dichos cambios en el aparato crítico de la edición supone un recurso metodológico para registrar y desplegar la historia de transmisión y recepción del texto. Por ello, proponemos un modo de anotación que hemos implementado en nuestra edición crítica de los impresos castellanos del libro de Mandevilla, según exponemos a continuación.

En primer lugar, indicamos la presencia de entalladuras en donde éstas aparecen. Dado que las mismas difieren según los testimonios, señalamos cada caso con el siguiente tipo de anotación, en el cuerpo del texto: <XIL. 1> (xilografía presente en 1521 y en el resto de los impresos; el número indica el

${ }^{15}$ RUBIO TOVAR, Joaquín. La vieja diosa. De la Filología a la posmodernidad. Alcalá de Henares: Centro de Estudios Cervantinos, 2004, p. 423. 
orden de aparición); <XIL. 2; 1547 om.> (grabado presente en todos los testimonios excepto en el de 1547, que lo omite); <XIL. 3; 1547 alt.> (xilografía presente en todos los testimonios, excepto en el de 1547, que la cambia por otro grabado); <XIL. 4; 1531 var.> (el impreso de 1531 coloca una entalladura esencialmente igual a la xilografía 4 pero con algún detalle diferenciador o agregado en el dibujo, que la convierte en una variación de aquélla); <XIL. 1524 I>, <XIL. 1531 I >, <XIL. 1540 I > o <XIL. 1547 I> (estampas agregadas por los impresos de referencia, y orden de aparición de las mismas, señalado con numeración romana). Asimismo, al final de cada capítulo acompañamos dos tipos de notas: a) notas críticas explicativas sobre aspectos textuales, que dan cuenta de algunas lagunas o reducción del contenido textual, amplificaciones y variaciones textuales significativas con respecto a otros testimonios conservados, tales como el único manuscrito en lengua hispánica, el aragonés Esc. M-III-7, y otros testimonios franceses manuscritos e impresos, y b) variantes xilográficas, en las que se señalan y reproducen las variantes en los grabados de los distintos testimonios, con una breve descripción de la estampa introducida en cada caso, a fin de que los lectores puedan establecer comparaciones con las originales. Por último, en el Anexo IV (Grabados) que acompaña la edición, se numeran, describen, cotejan e identifican las estampas xilográficas de todos los testimonios en un cuadro comparativo ${ }^{16}$.

Si filólogos de la talla de Pasquali y Branca no olvidaron el alcance y la importancia del lenguaje iconográfico en los estudios filológicos, entendemos que, desde nuestra modestísima postura, debemos aportar los resultados de la propia experiencia en la edición del $L M M^{17}$. También Kurt

${ }^{16}$ En tal sentido, tomamos en cuenta los primeros impresos alemanes ilustrados, que servirán como modelo para los impresos castellanos y franceses posteriores: los de 1480 y 1481 (Ausgsburgo: Anton Sorg) y de 1482 (Augsburgo: Johan Schönsperger), así como también los impresos franceses de Lyon, c. 1490, s.e. [Nicolaus Philippi y Marcus Reinhart] y de Lyon, c. 1508, Claude Nourry, tanto para iluminar cuestiones textuales como iconográficas.

${ }^{17}$ Esta idea de que el lenguaje iconográfico debe ser estudiado en profundidad en pos de intereses filológicos no es nueva en absoluto. El gran maestro Giorgio PASQUALI (Storia della tradizione e critica del testo. Firenze: Le Lettere, $\left.2010\left[1934^{1}, 1952^{2}\right]\right)$, refiriéndose a la edición de textos antiguos, repasaba un caso emblemático con respecto a la datación de los manuscritos de Terencio. Dentro de la denominada recensión caliopiana, se distingue el grupo $\gamma$, que se caracteriza porque algunos de los testimonios llevan ilustraciones al comienzo de cada escena. El estudio de los dibujos y sus particularidades le permite a Pasquali comprobar que la fecha postulada por Günther JACHMANN (Die Geschichte des Terenztextes in Altertum. Basel: Reinhardt, 1924) para algunos de ellos (el siglo IV) sería errónea, y que la misma debería retrasarse hasta el siglo $\mathrm{V}$ o incluso VI si se toman en cuenta los detalles históricos que aportan las ilustraciones (sobre vestimenta, arquitectura, armas de los soldados, etc.). Asimismo, el análisis de las imágenes también permitiría determinar el manuscrito sobre el cual se habría basado el texto ilustrado, a la vez que, en aquellos casos en que las imágenes no se ajustan estrictamente al texto (por ejemplo, cuando se dibujan per-

Revista de Literatura, 2011, enero-junio, vol. LXXIII, n. ${ }^{\circ}$ 145, 143-164, ISSN: 0034-849X 
Weitzmann, desde el punto de vista artístico, abordó en los años '40 la relación entre texto y miniaturas a través del estudio comparativo de los ciclos de imágenes que ilustraban el Antiguo Testamento y los orígenes de dicho corpus iconográfico. Sus ideas a menudo remiten a la crítica textual, cuya metodología pone en correlato con la crítica pictórica, señalando similitudes y diferencias entre ambas disciplinas, las cuales comparten el mismo mundo u objeto, el rollo y el códice:

A la hora de hacer la historia de la ilustración de un determinado texto, hemos de tener en cuenta no sólo los manuscritos que conservan la conexión que había entre las miniaturas y el texto base, sino también las refundiciones textuales que contienen escenas entresacadas del ciclo pictórico original ${ }^{18}$.

La interesante problemática acerca de los motivos por los cuales el lenguaje iconográfico merece ser atendido en el trabajo ecdótico podría resumirse en los ejemplos que siguen, tomados de la tradición mandevillesca.

El primer caso curioso y claramente ilustrativo del fenómeno que buscamos estudiar nos lo brinda la descripción de los habitantes de cierta isla, quienes comen carne y pescado crudo:

Ay assimesmo otra ysla donde non tienen las personas fruente de los ojos arri$b a$. Estas gentes van assi por sobre la mar como nosotros ymos por la tierra seca, y comen carne y pescado crudo $(1521,59 r)^{19}$.

El grabado que ilustra la escena muestra a un hombre semi-sumergido en el agua, tomando pescados. La característica más notable es que parece faltarle parte de la cabeza. En este lugar, las fuentes francesas traen una lección bien diferente, que coincide con la del manuscrito aragonés (transcribimos como ejemplo en francés el del Ms. BNF Fonds Smith Lesouëf 65 [P15], y a continuación, el fragmento según el manuscrito escurialense):

sonajes en actitudes que no corresponden a la escena), habría que buscar el origen de tal desajuste en una mala lectura por parte del ilustrador. Al respecto, ver también GRANT, John N. « $\Gamma$ and the miniatures of Terence». The Classical Quarterly, New Series, 1973, 23: 1, pp. 88-103. Otro reconocido filólogo italiano, Vittore BRANCA (Boccaccio visualizzato. Narrare per parole e per immagini fra Medioevo e Rinascimento, 3 vols. Torino: Einaudi, 1999), es quizás quien mejor representa esta corriente que aúna el estudio de la relación entre texto e imágenes, a través de su monumental trabajo sobre los manuscritos ilustrados de las obras de Boccaccio, en el cual busca catalogar y clasificar las más de 7000 imágenes que los ilustran. Branca establece cómo la literatura boccacciana puede resumirse en imágenes, las cuales enfatizan detalles de la trama narrativa que orientan la interpretación del texto. El mismísimo Boccaccio se vuelve así un «autor-intérprete» de su propia obra cuando debió indicar qué tipo de imágenes eran convenientes para aclarar el sentido de sus novelas e incluso a través de su participación como ilustrador de sus propios textos.

${ }^{18}$ WEITZMANN, Kurt. El rollo y el códice. Un estudio del origen y el método de la iluminación de textos. Madrid: Nerea, 1990 [1970], p. 102.

${ }^{19}$ Todas las citas de los impresos castellanos de Mandevilla están tomadas de nuestra edición crítica (RODRÍGUEZ TEMPERLEY, Mercedes (ed.), op. cit., 2011), que se reproducen con el correspondiente aparato crítico. 
y a vne autre ysle ou les gens sont tous peluz fors la face et les paumes/ celles gens vont aussi bien par dessuz la mer comme par dessuz la terre seche et menguent poisson et char creue (P15 85r; Deluz, 2000, p. 461) ${ }^{20}$

ay vna otra villa do las gentes son todos peludos sino que la cara et las palmas. Aquellas gentes van assi bien por medio de la mar como por la tierra et comen carne et pescado todo crudo (Esc. 85v);

Esta variante textual motivó la atención de la investigadora italiana Lidia Bartolucci $^{21}$, quien vio esta lectura como ajena a la tradición textual insular a la cual adscribe esta porción del texto castellano, lo cual la llevó a indagar en multiplicidad de manuscritos mandevillescos en busca de esta variante que no encontró en otros testimonios. Lo curioso es que los impresos alemanes precedentes ofrecen el mismo grabado pero con la cabeza completa. Una de las explicaciones posibles es que el taco xilográfico utilizado en las ediciones castellanas estuviera roto, o fuera copia de uno que ya estaba dañado. Por ese motivo, los impresos de Valencia 1521 y 1524 describen el grabado, añadiendo sólo «non tienen las personas fruente de los ojos arriba» $(1521,59 \mathrm{r} ; 1524,50 \mathrm{r})$, mientras que las ediciones posteriores (Valencia 1531, 1540 y Alcalá 1547) refuerzan: «a manera de media cabeça». Los impresos franceses reproducen una viñeta similar a las de los impresos castellanos (es decir, con la frente amputada), pero el texto es más fiel al arquetipo, sin introducir las variantes que presentan las ediciones peninsulares, las cuales no están siguiendo ninguna fuente previa o modelo en particular sino que buscan reponer en el texto aquellos aspectos que muestra el grabado utilizado para ilustrar la descripción:

Ay assimesmo otra ysla donde non tienen las personas fruente de los ojos arriba (Valencia, 1521, 59r; Valencia,1524, 50r) Todas aquellas gentes que en ella biuen no tienen frente de los ojos arriba, 'a manera de media cabeça’ (Valencia, 1531,
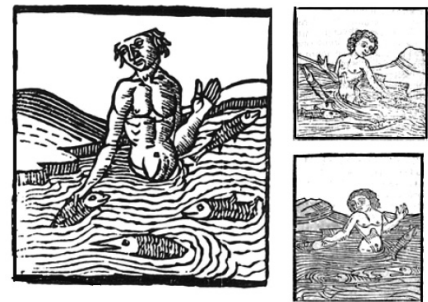

Augsburgo:

Anton Sorg, 1480, 1481

Augsburgo: Johan Schönsperger 1482 59r; 1540, 57r; Alcalá $1547,54 \mathrm{r}$ )

Apres de ceste isle en ya vne autre ou les gens sont tous velus fors le visaige et vont par la mer et par la terre comme les aultres et ne mengent que chair et poisson tout cru (Lyon 1490, p. 132; Lyon 1508: fol. 61r)

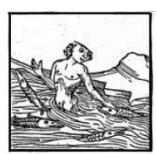

Lyon: [Nicolaus Philippi y Marcus Reinhart], c. 1490; Lyon: Claude Nourry, ¿1508?]

${ }^{20}$ DELUZ, Christiane (ed.). Jean de Mandeville: Le livre des merveilles du monde. Édition critique. Paris: CNRS Editions, 2000. Se trata de la única edición crítica de la tradición insular en francés del $L M M$.

${ }^{21}$ BARTOLUCCI, 2008, op. cit., p. 614. 
No es el único caso en que un grabado genera variantes textuales, producto de la descripción o comentario de los impresores o cajistas sobre la imagen que tienen ante sí:

En otra ysla ay gentes que tienen los pies como cauallos ${ }^{22}$, e tienen $\operatorname{cuernos}^{23}, \mathrm{y}$ son muy poderosas gentes y grandes corredores, porque ${ }^{24}$ corriendo toman las bestias saluajes y se las comen $(44 \mathrm{v})$

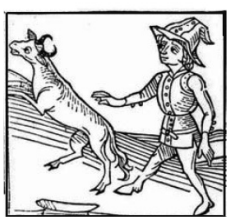

Augsburgo 1480-1481; Lyon 1490, p. 99; Lyon 1508, 46v

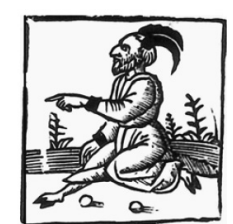

Valencia $1521,44 \mathrm{v}$ 1531,1540 y copia de Alcalá 1547

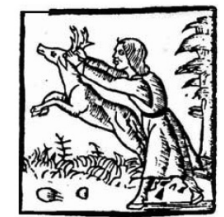

Valencia, 1524, 45r

Las estampas de todas las ediciones castellanas provienen en este caso del Liber Chronicarum de Hartmann Schedel (Nüremberg: Anton Koberger, 1493). Como resulta fácil advertir, no han tomado el modelo alemán de Anton Sorg. Por ello, los grabados de las ediciones castellanas son acompañados por variantes textuales, en un todo de acuerdo con la descripción de dichas entalladuras: los pies como «cabras» (para 1531, 1540 y 1547) y como «cauallos» para 1524. Este último testimonio omite que estas gentes tengan «cuernos» (porque de hecho, en la estampa no los tienen, a diferencia de la que aparece en los otros impresos de 1521, 1531, 1540 y 1547, donde los cuernos son acaso el rasgo más sobresaliente).

Existen otros casos de desviación del arquetipo iconográfico original. Un ejemplo proviene de la edición de Alcalá de Henares de 1547, que inserta ocho grabados procedentes de la Legenda Aurea Sanctorum (Basel: Nicolaus Kesler, 1486). El problema surge al comparar las entalladuras presentes en las otras ediciones castellanas y advertir que las imágenes de la de Alcalá provocan «desajustes semánticos» entre lo que dice el texto y lo que muestra la xilografía.

Al respecto, los casos más llamativos resultan ser una escena hagiográfica en la que un mártir de rodillas es atravesado por la lanza de un soldado ante la negativa de adorar un ídolo, utilizado por el impreso alcalaíno para ilustrar la muerte de Abel a manos de Caín (fol. 27v). Otro ejemplo corresponde a un grabado que ilustra cómo un grupo de soldados mata

\footnotetext{
22 cauallos] cabras $1531,1540,1547$.

${ }^{23}$ e tienen cuernos] om. 1524.

${ }^{24}$ porque] que $1531,1540,1547$.
} 
cruelmente a varios niños mientras una mujer llora arrancándose los cabellos (indubitable imagen de los Santos Inocentes), utilizado en el impreso de 1547 para representar la costumbre de comprar y vender niños en la región de Lamoy (fol. 39v). Por último, verificamos otra escena de martirio, en la cual un verdugo se halla presto para decapitar a un santo con nimbo, en reemplazo de la que ilustraba el rito funerario de los habitantes del reino de Riloch (fol. 61r), donde al morir el padre, un sacerdote se encargaba de cortarle la cabeza, la colocaba en un plato y se la entregaba al hijo (esto es lo que muestra la xilografía del resto de las ediciones castellanas, copia de la de Sorg). La comparación entre las imágenes de los primeros impresos, fieles a la tradición iconográfica germana, y las estampas utilizadas en la edición castellana de Alcalá 1547, inevitablemente revela la incidencia que sobre los lectores puede tener el tomar una u otra edición, ya que las escenas de violencia o costumbres de pueblos paganos o idólatras se convierten en martirios cristianos, elocuentes imágenes de santorales que nada tienen que ver con las «maravillas», idolatrías o rarezas de tierras lejanas ${ }^{25}$.

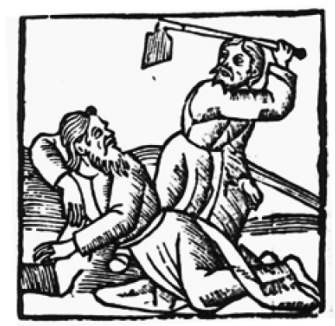

Valencia $1521,27 \mathrm{v}$; Valencia 1524, 27r;

Valencia 1531, 27r; Valencia, 1540, 26r

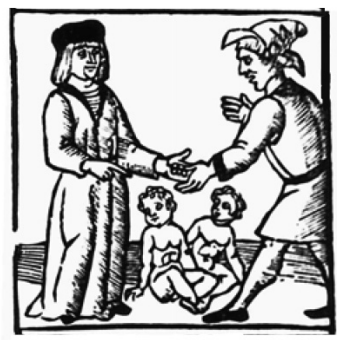

Valencia $1521,39 \mathrm{v}$; Valencia $1524,39 \mathrm{v}$; Valencia 1531, 39v; Valencia, 1540, 38r

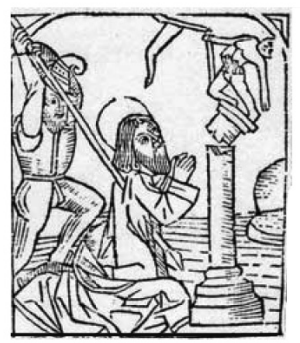

Alcalá de Henares 1547, 24r

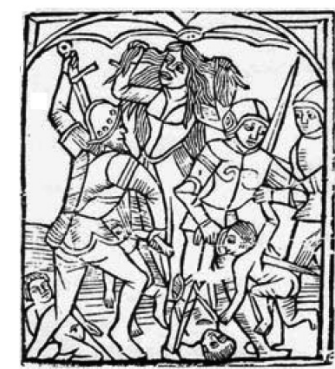

Alcalá de Henares 1547, 35v

\footnotetext{
${ }^{25}$ Las imágenes tomadas de la Legenda Aurea Sanctorum (Basel: Nicolaus Kesler, 1486) corresponden, respectivamente, a la Vida de Santo Tomás Apóstol, De Innocentibus y De septem fratibus qui fuerunt filis beati felicitatis y De septem machabeis (la misma estampa es utilizada para ilustrar estas dos últimas vidas de santos).
} 


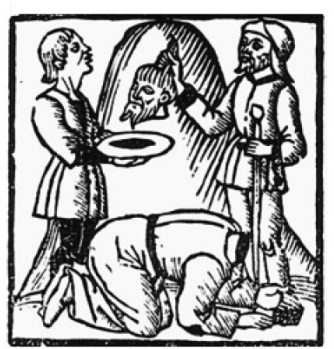

Valencia 1521, 61r; Valencia 1524, 61v; Valencia 1531, 61r; Valencia, 1540, 58v

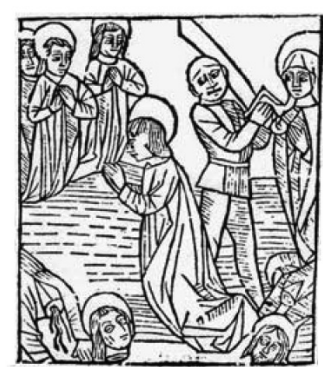

Alcalá de Henares 1547, 55r

Ya Moseley ${ }^{26}$ se había referido a las «metamorfosis» del Libro de las maravillas en sus distintas versiones. Lo que este autor advirtió en el plano textual tendría también su correlato en el plano iconográfico. Es obvio que el cambio de grabados en la edición alcalaína de 1547 da como resultado una suerte de «versión piadosa» del $L M M$, sobre todo si tomamos en cuenta el altísimo grado de influencia que tenían las imágenes sobre quienes no sabían leer pero que sin embargo mantenían relación con los libros. También el impreso de Valencia 1524 se caracteriza por el añadido de numerosas xilografías con escenas de la vida de Cristo, de la Virgen María y otros temas piadosos, lo cual le confiere a dicha edición una identidad propia y particular, ausente del resto de los testimonios castellanos.

Los impresos alemanes del Augsburgo traen a continuación de la portada una estampa a plana entera que representa a un joven Juan de Mandevilla, en la cual se lo muestra de pie, con su espada de caballero, un estandarte y una cruz en la frente que simboliza su carácter de peregrino a Tierra Santa, y una filacteria con la leyenda «Johannes de Montevilla». Este grabado está ausente de los impresos castellanos, aunque no de los franceses, como los de Lyon c. 1490 y c. 1508, que lo reproducen. Es costumbre que luego del colofón se añada la marca del impresor o alguna viñeta decorativa (orlas, etc.). Lo curioso es que dos impresos, el de Lyon (Claude Nourry, c. 1508) y el de Valencia (Joan Navarro, 1540) incorporan dos entalladuras que el resto de las ediciones omite. El impreso francés repite el grabado que ya figuraba en la portada: un caballero jinete, al más puro estilo de los que ilustraban los libros de caballerías. El impreso valenciano, por el contrario, añade la figura de un escritor en su pupitre, tomada de la Suma de todas las crónicas del mundo (Valencia: Jorge Costilla, 1510, fol. 1r). ¿Cuál podría ser el motivo de esta inclusión tan di-

${ }^{26}$ MOSELEY, C. W. R. D. «The Metamorphoses of sir John Mandeville». Yearbook of English Studies, 1974, 4, pp. 5-25. 
versa? La clave está en las palabras con las que Juan de Mandevilla, el autor, cierra su libro:

Es de saber que yo, Johan de Mandauila ${ }^{27}$, 'cauallero susodicho', me parti de mi tierra y passe [1]a mar en el año de la gracia y salud de la natura ${ }^{28}$ humana de mill y .ccc. y .xxij. años. Y despues aca he andado muchos passos y tierras ${ }^{29}$, y he estado en compañias buenas y en muchas y diuersos fechos bellos y en grandes enpresas $^{30}$. Agora soy venido a reposar en edad de viejo antiguo ${ }^{31}$, y acordandome de las cosas passadas, 'he escripto' ${ }^{32}$ como mejor pude aquellas cosas que vi y oý por las tierras por $^{33}$ donde anduue... (fol. 62r)

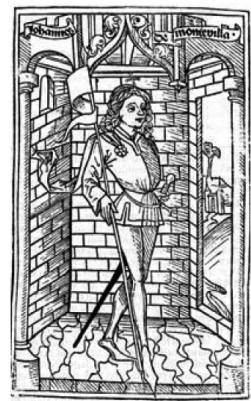

Augsburgo, 1480

Lyon c. 1490 y c. 1508

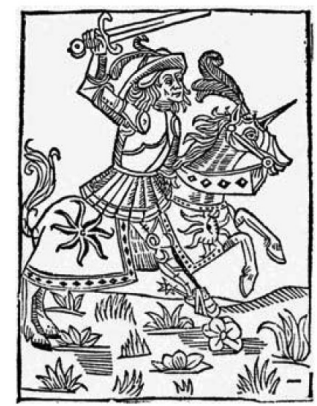

Lyon, c. 1508

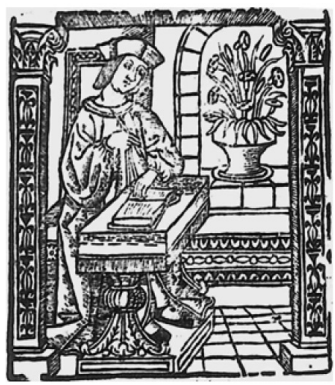

Valencia, 1540

A través de la elección del grabado, el impreso de Lyon c. 1508 privilegia la figura del «cauallero susodicho», es decir, del «caballero viajero» (recordemos la extensa y difundida tradición europea, que identificaba a Mandevilla como un «caballero inglés nacido en St. Albans»). La iconografía caballeresca en boga le aportó esa figura, que reproduce la estampa de un hombre de acción, en consonancia con las aventuras vividas durante el maravilloso y largo viaje por tierras extrañas y en clara analogía con la representación iconográfica de los exitosos libros de caballerías, de difu-

${ }^{27}$ Johan de Mandauila] Juan de Mandauilla 1531, 1540, 1547.

${ }^{28}$ de la natura] om. 1531, 1540, 1547.

${ }^{29}$ muchos pasos y tierras] muchas tierras y passos peligrosos 1531, 1540, 1547.

${ }^{30} \mathrm{y}$ he estado en compañias buenas y en muchas y diuersos fechos bellos y en grandes enpresas] heme hallado en muchos hechos notables y dignos de inmortal memoria 1531, $1540,1547$.

${ }^{31}$ Agora soy venido a reposar en edad de viejo antiguo] Y como sea cosa natural y de mucha razon nadie no poder oluidar su patria natural, pues assi yo, despues de auer casi rodeado todo el mundo y ya cargado de la complida vejez |complida y anciana vejez 1540; complida vejez 1547|, acorde de venir a reposar a la mia 1531, 1540, 1547.

${ }_{32}$ escripto] escrito 1531, 1540, 1547.

${ }^{33}$ por] om. 1531, 1540, 1547. 
sión masiva durante esos años. El impreso valenciano de 1540, por el contrario, rescata la figura erudita, enciclopédica, la del Mandevilla anciano («en edad de viejo antiguo») que escribe los recuerdos de su travesía. De esta manera, ambos grabados «guían» a los lectores en la identificación de figuras autoriales que se muestran como antagónicas o contrapuestas: el viajero intrépido y aventurero de la juventud y el escritor anciano que, en el reposo de su scriptorium, revive su itinerario a través de una narración tardía ${ }^{34}$. Dichas figuras, en honor a la verdad, deberían ser complementarias, por tratarse de la misma persona que ensaya en realidad dos formas distintas del mismo viaje: la experiencia práctica y la experiencia de escritura.

Uno de los aspectos más sobresalientes en las versiones castellanas con respecto a otras traducciones europeas del $L M M$, consiste en el espacio dedicado a las razas monstruosas. Éstas, prototipo de las «maravillas» que configuran la alteridad en los confines del mundo, ya tenían un lugar destacado en el título y portadas de las ediciones españolas: Libro de las marauillas del mundo y del Viaje de la Tierra Sancta de Jerusalem y de todas las prouincias y cibdades de las Jndias y de todos los ombres mostruos que ay por el mundo, con muchas otras admirables cosas.

Las estampas que ilustran de las portadas sólo se refieren a los hombres monstruos o razas plinianas, y se van incrementando en las sucesivas ediciones: los impresos de 1521, 1524 y 1540 llevan cuatro grabados; el de 1531, ocho, y el de 1547, diez. Esto significa que la táctica comercial de los impresores peninsulares para provocar la atención en los lectores del $L M M$ era, indudablemente, la temática monstruosa.

Pero lo que evidencian en un comienzo las portadas y el título, tiene también su correspondencia dentro del texto, a través del incremento de grabados de «ombres mostruos», las cuales, tomando como modelo las del Liber Chronicarum de H. Schedel (Nüremberg: Anton Koberger, 1493), reemplazan los grabados del arquetipo iconográfico germánico ideados por Anton Sorg y suman nuevos monstruos a los ya existentes.

En el folio 45r de la edición de Valencia 1521 (seguida por todas las otras ediciones valencianas) se añaden ocho xilografías que ilustran razas monstruosas, tomadas del mencionado Liber Chronicarum, lo cual significa que no pertenecen a la tradición iconográfica germana del libro de Mandevilla. Con el objeto de que tal incremento xilográfico no quede sin la debida explicación discursiva, se agrega contenido textual que interpreta y describe las figuras, «creando» así nuevos monstruos, que no figuran en

\footnotetext{
${ }^{34}$ A pesar de que Mandevilla fue un «viajero de escritorio» que escribió su relato a partir de una hábil combinación de otros existentes y no de su propia experiencia de un viaje real, siempre se lo consideró como un gran viajero que había visto lo que describía en su Libro, y así fue leído.
} 
ninguna de las versiones o traducciones conocidas del libro de Mandevilla, excepto en la tradición castellana. Dichas adiciones, además, incluyen referencias a fuentes y auctoritates («las escrituras de Alexandre Magno», «un dotor llamado Sigon y otro que dizen Menfodoro») $)^{35}$, algo que a todas luces es ajeno a la tradición textual mandevillesca, debido a que nuestro autor se caracterizó siempre por mostrar el relato de su viaje como producto de su propia experiencia y no de sus lecturas, obviando toda mención a fuentes previas e incluso a auctoritates, a excepción de la Biblia.
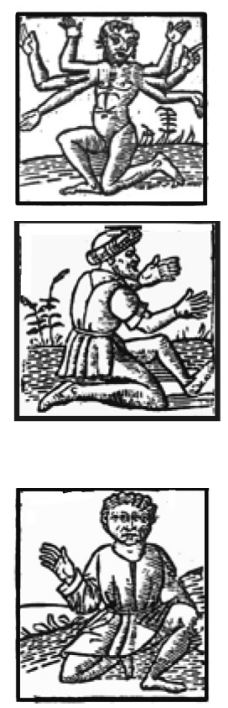

En las escrituras de Alexandre Magno ${ }^{36}$ se lee que en ${ }^{37}$ vna prouincia de la India llamada Sitia ay ${ }^{38}$ vnos ombres los quales tienen seys braços y seys manos, y hazen hazienda con el que quieren. <XIL. 89; 1547 var.>

Item en la dicha India ay vnos ombres que son tan vellosos ${ }^{39}$ que parecen vnos osos, y lo mas del tiempo biuen dentro de la agua ${ }^{40}$, y alli es su abitacion. $<$ XIL. 90> Ay mas en la dicha Jndia, hvna tierra bien grande en la qual abitan ombres y mugeres, los quales tienen seys dedos en cada mano y otros seys en cada pie. <XIL. 91>

Part[i]mos de aquesta tierra y llegamos a vna prouincia, la qual era muy abundosa y muy fertil de muchos arboles y de muchas maneras de frutales modernos a nosotros, en la qual tierra todas las mugeres tienen baruas como si fuessen ombres, y no ti[e]nen cabello $^{41}$ en $^{42}$ la cabeça. <XIL. 92; 1547 var.> De aqui

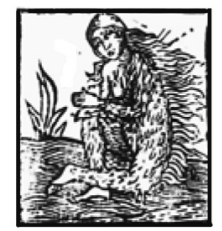
fuymos $^{43}$ a vna prouincia que se llama Etiopia Occi-

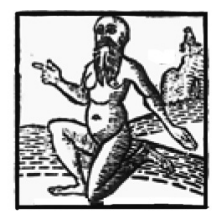
dental, en la qual abitan vna manera de ombres que tienen en medio de la frente quatro ojos y vehen con qualquiera d'ellos.

${ }^{35}$ En el primer caso, se trata seguramente de la Historiae Alexandri Magni Macedonis, escrita por Quinto Curcio Rufo, mientras que Sigón y Menfodoro son en realidad Isigonus de Niquea (s. I a. C.) y Nymphodorus (s. III a. C), dos geógrafos y paradoxógrafos citados por Plinio en su Historia Natural: «in eadem Africa familias quasdam effascinantium Isigonus et Nymphodorus, quorum laudatione intereant probata, arescant arbores, emoriantur infantes» (Plinius, Naturalis Historia, Liber VII, 16).

${ }^{36}$ de Alexandre Magno] del Rey Alexandre Magno 1540.

$\left.{ }^{37} \mathrm{en}\right]$ es $1521,1524,1531,1540$.

${ }^{38}$ ay] e ay 1524 | que ay 1540.

${ }^{39}$ vellosos] vellos 1521 .

${ }^{40}$ de la agua] del agua 1540 .

${ }^{41}$ cabello] cabellos 1540 .

42 en] om. 1531.

${ }^{43}$ fuymos] huymos 1531 | fuemos 1540. 


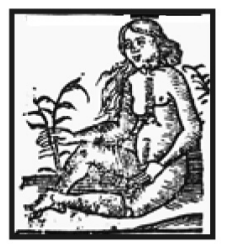

Un dotor llamado Sigon y otro que dizen Menfodoro escriue ${ }^{44}$ que en Africa ay mugeres barbudas, las quales saben tantas artes diabolicas que hazen secar los arboles y matan los niños de ojo. <XIL.

93; 1547 om.>

Ay en la India ${ }^{45}$ vna isla en la qual biuen ombres de gran forma como gigantes, y non tienen sino vn ojo en medio de la frente, los quales no comen sino carne y pescado sin pan. <XIL. 94>

De aquesta isla va hombre en vna prouincia llamada Sitia, en la qual ay vn valle muy grande y muy fermoso que se llama en griego Antropofagos ${ }^{46}$. Y ay vnas gentes que tienen los pies al reues de nosotros, y son grandes corredores y andan siempre entre las bestias saluajes. <XIL. 95; 1547 om. $>$ [fol. 45v] (pp. 177-178)

Esto significa que una de las porciones textuales más importantes del $L M M$ castellano y una de las escasas en las que se citan otros autores, no sólo no es original de Juan de Mandevilla sino la obra de algún cajista, componedor o impresor del siglo XVI. Y en este caso, el origen de la amplificatio radica en el componente iconográfico.

Lo mismo ocurre unos folios más adelante, con la descripción de los hombres que tienen cuello de grulla y de los panoti, hombres con orejas tan grandes que parecen mangas de tabardo, amplificación motivada, nuevamente, por la inserción de estampas provenientes del Liber Chronicarum:

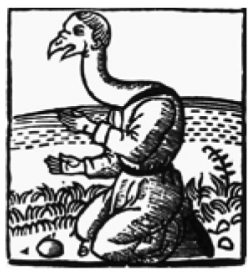

En la India ay vna prouincia llamada Etiopia, en la qual biuen vna manera de gentes, los quales tienen buena dispusicion ${ }^{47}$ de cuerpos y manos y pies ni mas ni menos que nosotros tenemos $<$ XIL. 100; 1547 var.> aca. Empero ellos tienen el cuello tan largo como vna grulla, y la frente y los ojos como ombre, y el rostro agudo como de vn perro ho de vna grulla. $<$ XIL. 101; 1547 om.>

En la prouincia de Sitia, en ${ }^{48}$ vnas grandes y altas montañas donde ay diuersos arboles con hartas maneras de frutales $^{49}$, y en aquestas sobredichas montañas biuen vna manera de gentes, los quales se llaman 'panoti', e tienen toda la manera assi como nosotros, saluo que tienen las orejas tan grandes ${ }^{50}$ que parescen man-

${ }^{44}$ escriue] escriuen 1540.

${ }^{45}$ en la India] en las Indias $1540 \mid$ es add. 1531.

46 Antropofagos] Antropophagos 1540.

${ }^{47}$ dispusicion] disposicion 1531, 1540, 1547.

48 en] ay $1531,1540,1547$.

49 frutales] frutas $1531,1540,1547$.

${ }^{50}$ los quales se llaman 'panoti', e tienen toda la manera assi como nosotros, saluo que tienen las orejas tan grandes] que se llaman 'panoti |panotis 1547|, los quales tienen todos los miembros assi como nosotros saluo las orejas, que las tienen tan grandes 1531, 1540, 1547. 
gas de tauardo, con las quales ${ }^{51}$ se cubren todo el cuerpo, y tienen la boca redonda como vn escudilla $^{52}$. [fol. 47r]

Halla ombre otra ysla adonde biuen gentes que andan a cuatro pies $^{53}$, y son todos vello$\operatorname{sos}^{54}$ e subense por los arboles muy prestamente ${ }^{55}$ como si fuesen ximios, y van ${ }^{56}$ desnudos.

$\mathrm{Un}^{57}$ otra isla ay cerca d'esta, en la qual ay gentes que andan sobre las rodillas muy marauillosamente porque parece que a cada paso deuen $\operatorname{caer}^{58}$, e tienen en cada pie ocho dedos. Otras maneras de gentes ay por aquellas islas, y por euitar prolixida[d] passo breuemente ${ }^{59}$.

Con respecto a las citas de autoridades, el Prohemio al Libro II que aparece en las ediciones castellanas no existe en las versiones francesas del Mandevilla. Evidentemente, en las traducciones castellanas se apela a las auctoritates (Plinio, San Agustín, San Isidoro y el Cronicon mundi o Liber Chronicarum) para otorgar un viso científico y verosímil a la materia maravillosa, temática que prevalecerá en esta segunda parte del libro y de la cual ya hemos resaltado su importancia:

En aqueste segundo libro se tracta ${ }^{60}$ de muchas y diuersas marauillas que son por el mundo repartidas, y porque especialmente en las Jndias ${ }^{61}$ ay muchas admirables cosas y quasi impossibles de creer, pareciome a mi enpremtando la presente obra ${ }^{62}$ que entre las otras cosas que $\operatorname{con}^{63}$ el presente libro ay de marauillar es auer hombres de tal manera produzidos. ${ }^{64}$ Quise saber y ver por muchos libros si era verdad que tales hombres ouiese por el mundo y hallelo escrito por diuersos dotores ${ }^{65} \mathrm{di}$ nos $^{66}$ de fe y de creer: que ay hombres mostruos ${ }^{67}$ de tales formas como en el pre-

\footnotetext{
${ }^{51}$ con las quales] y con ellas $1531,1540,1547$.

${ }^{52}$ como vn escudilla] assi como vna $\mid v n$ 1540| escudilla 1531, 1540, 1547.

${ }^{53}$ adonde biuen gentes que andan a cuatro pies] adonde biuen hombres que andan a cuatro pies 1531,1547 | donde biuen hombres que andan en quatro pies 1540 .

54 vellosos] vellos 1521 | pelosos 1524 .

55 muy prestamente] assi 1531, 1540, 1547.

56 van] andan $1531,1540,1547$.

57 un] una $1531,1540,1547$.

${ }^{58}$ andan sobre las rodillas muy marauillosamente porque parece que a cada paso deuen caer] andan a quatro pies por cierto que es cosa marauillosa de ver, porque paresce que a cada paso han de caer 1531, 1540, 1547.

${ }^{59}$ Otras maneras de gentes ay por aquellas islas, y por euitar prolixidad passo breuemente] Otras maneras de gentes ay por estas islas, las quales por euitar prolixidad me passo breuemente $1531,1540,1547$.

${ }^{60}$ tracta] trata $1531,1540,1547$.

${ }^{61}$ en las Jndias] en las tierras de la Jndia 1531, 1540, 1547.

${ }^{62}$ enpremtando] empremiendo 1524 |emprentando 1531| imprimiendo 1547| pues que la presente obra se hazia imprimir 1540.

${ }^{63}$ con] en $1531,1540,1547$.

${ }^{64} \mathrm{y}$ por lo tanto add. 1540 .

65 dotores] doctores 1540 .

${ }^{66}$ dinos] dignos $1531,1540,1547$.

${ }^{67}$ que ay hombres mostruos] que ay hombres monstruos 1531,1547 | que dizen que ay hombres monstruos 1540 .
} 
sente libro hallareys. Porque lo dize Plinio (libro .vij., capitulo .ij.) ${ }^{68}$ y Sant Agostin (libro .xvj. de Ciuitate Dei, capitulo .viij. ${ }^{69}$ ) y Esidro ${ }^{70}$ en las Etimologias (libro .xj., capitulo .iij. ${ }^{71}$ ) y avn en el Cronica mundi ${ }^{72}$ los hallareys asi pintados como la vida suya $^{73}$, y pues que aquesto es verdad, no es de marauillar de ninguna cosa de las otras que aqui estan.

En repetidas ocasiones se ha definido el género literario de los libros de viajes como un tipo de discurso narrativo o descriptivo en el cual la segunda función absorbe a la primera ${ }^{74}$. Como afirma Alburquerque García (2006, p. 79),

en los relatos de viajes, ya sean medievales, renacentistas, barrocos, dieciochescos, del XIX o contemporáneos, las posibles tensiones narrativas, al estar subordinadas a la descripción - de lugares, personas o situaciones-, se deshacen durante el propio desarrollo del relato. En definitiva, su naturaleza específica radica en la belleza de las descripciones y, esporádicamente, en la tensión narrativa de episodios aislados, cuyo clímax y anticlímax se resuelve puntualmente y no en el nivel del discurso.

Entendemos que todo procedimiento de ilustración de un texto tiene por objeto hacer más precisa la descripción textual. En este sentido, los grabados no harían más que auxiliar a las descripciones dentro del relato, con el objeto de apoyar la imaginación del lector para que éste pueda interpretar lo más fielmente posible aquello que el mediador del discurso (en este caso, suponemos que el impresor) pauta como correcto. En efecto, «si la narración consiste en relatar con palabras sucesos que los seres llevan a cabo, la descripción, por el contrario, trata de «pintar» con palabras, de manera que el receptor pueda ver mentalmente la realidad descrita» ${ }^{75}$ ¿ ¿No es ésta, acaso, una definición aplicable no sólo al discurso analítico sino también al lenguaje de la imagen?

Por todo ello, proponemos como línea de trabajo la consideración del lenguaje iconográfico en las ediciones críticas con sus diversas problematizaciones, a saber: a) relación de los grabados con el contenido textual que ilustran, b) relación de las estampas con las variantes textuales introducidas a partir del ajuste o desajuste entre éstas y el texto, c) filiación de las variantes iconográficas, con el objeto de distinguir las que correspon-

${ }^{68}$ libro .vij., capitulo .ij.] libro septimo, capitulo segundo 1540 .

${ }^{69}$.viij.] septimo 1540.

${ }^{70}$ Esidro] Esidoro 1524 | San Esidro 1540 | San Ysidoro 1547.

${ }^{71}$ capitulo .iij.] capitulo tercero 1540.

72 en el Cronica mundi] en el |la 1540| Coronica mundi 1531, 1540, 1547.

${ }^{73}$ como la vida suya] como |con 1547| la vida y condiciones suyas 1531, 1540, 1547

${ }^{74}$ Al respecto, ver CARRIZO RUEDA, Sofía. Poética del relato de viajes. Kassel: Reichenberger, (Problemata Literaria, 37), 1997, y Luis ALBURQUERQUE GARCÍA. «Los 'libros de viaje' como género literario». En: LUCENA GIRALDO, Manuel y Juan PIMENTEL (eds.). Diez estudios sobre literatura de viajes. Madrid: CSIC, 2006, pp. 67-87.

${ }^{75}$ ALBURQUERQUE GARCÍA, Luis, 2006, op. cit., pp. 76-77. 
den originalmente al «arquetipo iconográfico», las que han sido cambiadas por otras ajenas al lenguaje artístico propio del libro original, las omitidas y las que se añaden, con el objeto de distinguir a qué otros géneros pertenecen (santorales, libros de caballerías, libros de viajes, crónicas, etc.).

Tal como enunciáramos más arriba, consideramos que obviar u omitir en las modernas ediciones críticas el rico lenguaje iconográfico que acompañaba los impresos antiguos desvirtúa el objeto cultural que buscamos estudiar y esclarecer para una mejor comprensión por parte de los lectores contemporáneos. Ya Pasquali (1934) destacaba la singularidad de cada tradición, interpretando que los testimonios no eran simples portadores de errores y variantes sino el producto de determinada configuración cultural acorde a su época. Por otra parte, en sus definiciones acerca del valor de una edición crítica, Contini (1977 [1986: 45-46]) señalaba que una de sus funciones consistía en reabrir un texto cerrado y estático para hacerlo abierto y dinámico, es decir, reproponerlo en el tiempo, y que así como una investigación etimológica no debería borrar las fases de la historia de una palabra, el objetivo de una investigación ecdótica no siempre necesita la reconstrucción del texto original, sino de momentos de «fortuna» textual. En este sentido, consideramos que en ciertos casos de tradiciones textuales complejas, en las cuales los textos hipotéticos ocupan más espacio en el stemma que los testimonios conservados, más viable que la búsqueda de un modelo subyacente perdido es la interpretación cultural que surge a partir del estudio de variantes aportadas por los distintos testimonios que han llegado hasta nosotros. $\mathrm{Y}$ es indudable que las imágenes son portadoras de sentido, y parte esencial de la transmisión y recepción del texto en su época: ni más ni menos que la encarnación de la vieja idea de «texto en el tiempo», que es la que guía nuestro trabajo ecdótico.

\section{REFERENCIAS BIBLIOGRÁFICAS}

ALBURQUERQUE GARCÍA, Luis. «Los 'libros de viaje' como género literario». En: LUCENA GIRALDO, Manuel y Juan PIMENTEL (eds.). Diez estudios sobre literatura de viajes. Madrid: CSIC, 2006, pp. 67-87.

BARTOLUCCI, Lidia. «A proposito delle versioni castigliani a stampa di Jean de Mandeville». Aevum, 2008, 82: 3, pp. 611-620.

—. «Intorno al Ms. P15 di Jean de Mandeville». En: BABBI, Anna María; Silvia, BIGLIAZZI y Gian Paolo MARCHI (eds.). Bearers of a tradition. Studi in onore di Angelo Righetti. Verona: Edizioni Fiorini, 2010, pp. 19-25.

BENNETT, Josephine W. The rediscovery of Sir John Mandeville. New York: Modern Language Association, 1954.

BLECUA, Alberto. Manual de Crítica Textual. Madrid: Castalia, 1983.

BRANCA, Vittore. Boccaccio visualizzato. Narrare per parole e per immagini fra Medioevo e Rinascimento. Torino: Einaudi, 1999, 3 vols.

CARRIZO RUEDA, Sofía. Poética del relato de viajes. Kassel: Reichenberger, 1997. Problemata Literaria, 37. 
CERQUIGLINI, Bernard. Eloge de la variante. Histoire critique de la philologie. Paris: Seuil, 1989.

CONTINI, Gianfranco. Breviario di ecdotica. Milano-Napoli: Riccardo Ricciardi Editore, 1986 [1970].

DAGENAIS, John. The Ethics of Reading in Manuscript Culture: Glossing the «Libro de buen amor». Princeton: Princeton University Press, 1994.

DELUZ, Christiane, (ed.). Jean de Mandeville: Le livre des merveilles du monde. Édition critique. Paris: CNRS Editions, 2000.

GRANT, John N. «Г and the miniatures of Terence». The Classical Quarterly. 1973, 23: 1, pp. 88-103. New Series.

JACHMANN, Günther. Die Geschichte des Terenztextes in Altertum. Basel: Reinhardt, 1924.

MOSELEY, C. W. R. D. «The Metamorphoses of sir John Mandeville». Yearbook of English Studies. 1974, 4, pp. 5-25.

ORDUNA, Germán. Ecdótica. Problemática de la edición de textos. Kassel: Edition Reichenberger, 2000.

PASQUALI, Giorgio. Storia della tradizione e critica del testo. Firenze: Le Lettere, 2010 $\left[1934^{1}, 1952^{2}\right]$.

RODRÍGUEZ TEMPERLEY, María Mercedes. «Variaciones textuales y cambios culturales en un libro de viajes. El caso de Juan de Mandevilla en España». En: ORDUNA, Germán et al. Estudios sobre la variación textual. Prosa castellana de los siglos XIII a XVI. Buenos Aires: Secrit 2001, pp. 169-195. Incipit Publicaciones, 6.

- (Ed.). Juan de Mandevilla: Libro de las maravillas del mundo (Ms. Esc. M-III-7). Edición crítica, estudio preliminar y notas. Buenos Aires: Secrit, 2005. Serie Ediciones Críticas, 3.

—. «Imprenta y variación textual: el caso de Juan de Mandevilla». Incipit, 2005-2006, XXVXXVI, pp. 526-536.

- (Ed.). Juan de Mandevilla: Libro de las marauillas del mundo y del Viaje de la Tierra Sancta de Jerusalem (Impresos castellanos, siglo XVI). Edición crítica, estudio preliminar y notas. Buenos Aires: IIBICRIT-SECRIT (Incipit Publicaciones. Ediciones Críticas 6, 2011.

ROSSEBASTIANO, Alda. La tradizione ibero-romanza del "Libro de las maravillas del mundo», di Juan de Mandavila. Alessandria: Studi, 1997.

RUBIO TOVAR, Joaquín. La vieja diosa. De la Filología a la posmodernidad. Alcalá de Henares: Centro de Estudios Cervantinos, 2004.

TENA TENA, Pedro. «Fuentes germanas en grabados de un texto de viaje a Tierra Santa: Juan de Mandeville (Valencia, 1524)». Gutenberg-Jahrbuch, 1996, 71, pp. 80-87.

WEITZMANN, Kurt. El rollo y el códice. Un estudio del origen y el método de la iluminación de textos. Madrid: Nerea, 1990 [1970].

Fecha de recepción: 21 de abril de 2010

Fecha de aceptación: 9 de diciembre de 2010 